\title{
Real-Time Monitoring of Brain Tissue Oxygen Using a Miniaturized Biotelemetric Device Implanted in Freely Moving Rats
}

\author{
Gianfranco Bazzu, ${ }^{\dagger}$ Giulia G. M. Puggioni, ${ }^{\dagger}$ Sonia Dedola, ${ }^{\dagger}$ Giammario Calia, ${ }^{\dagger}$ Gaia Rocchitta, ${ }^{\dagger}$ \\ Rossana Migheli, ${ }^{\dagger}$ Maria S. Desole, ${ }^{\dagger}$ John P. Lowry, ${ }^{\ddagger}$ Robert D. O’Neill, ${ }^{\S}$ and Pier A. Serra ${ }^{*}+$

\begin{abstract}
Department of Neuroscience, Medical School, University of Sassari, Viale S. Pietro 43/b, 07100 Sassari, Italy, Department of Chemistry, National University of Ireland, Maynooth, Co. Kildare, Ireland, and UCD School of Chemistry and Chemical Biology, University College Dublin, Belfield, Dublin 4, Ireland
\end{abstract}

A miniaturized biotelemetric device for the amperometric detection of brain tissue oxygen is presented. The new system, derived from a previous design, has been coupled with a carbon microsensor for the real-time detection of dissolved $\mathrm{O}_{2}$ in the striatum of freely moving rats. The implantable device consists of a single-supply sensor driver, a current-to-voltage converter, a microcontroller, and a miniaturized data transmitter. The oxygen current is converted to a digital value by means of an analog-to-digital converter integrated in a peripheral interface controller (PIC). The digital data is sent to a personal computer using a six-byte packet protocol by means of a miniaturized $434 \mathrm{MHz}$ amplitude modulation (AM) transmitter. The receiver unit is connected to a personal computer $(\mathrm{PC})$ via a universal serial bus. Custom developed software allows the $\mathrm{PC}$ to store and plot received data. The electronics were calibrated and tested in vitro under different experimental conditions and exhibited high stability, low power consumption, and good linear response in the nanoampere current range. The in vivo results confirmed previously published observations on oxygen dynamics in the striatum of freely moving rats. The system serves as a rapid and reliable model for studying the effects of different drugs on brain oxygen and brain blood flow and it is suited to work with direct-reduction sensors or $\mathrm{O}_{2}$-consuming biosensors.

Oxygen is the most important oxidative substrate for biochemical reactions and for the production of ATP in the brain. Tissue concentration of dissolved $\mathrm{O}_{2}$ is regulated by the balance between blood supply and local utilization ${ }^{1}$ and plays a key role in brain energy metabolism related to either glucose $\mathrm{e}^{2}$ or lactate ${ }^{3}$ used as energy substrates.

\footnotetext{
* Corresponding author. Phone: +39-079-228558. Fax: +39-079-228525. E-mail: paserra@uniss.it.

${ }^{\dagger}$ University of Sassari.

* National University of Ireland.

\$ University College Dublin.

(1) Lowry, J. P.; Boutelle, M. G.; Fillenz, M. J. Neurosci. Methods 1997, 71, 177-182.

(2) Fillenz, M. Neurochem. Int. 2005, 47, 413-417.

(3) Aubert, A.; Costalat, R.; Magistretti, P. J.; Pellerin, L. Proc. Natl. Acad. Sci. U.S.A. 2005, 102, 16448-16453.
}

The electrochemical reduction of oxygen is a complex process which can occur on the sensor surface via two mechanisms. In the first, complete reduction occurs in a single step, without the formation of detectable intermediates: ${ }^{4}$

$$
\mathrm{O}_{2}+4 \mathrm{H}^{+}+4 \mathrm{e}^{-} \rightarrow 2 \mathrm{H}_{2} \mathrm{O}
$$

In the second mechanism, reduction of oxygen occurs in two steps with the formation of hydrogen peroxide as measurable intermediate: ${ }^{4}$

$$
\begin{gathered}
\mathrm{O}_{2}+2 \mathrm{H}^{+}+2 \mathrm{e}^{-} \rightarrow \mathrm{H}_{2} \mathrm{O}_{2} \\
\mathrm{H}_{2} \mathrm{O}_{2}+2 \mathrm{H}^{+}+2 \mathrm{e}^{-} \rightarrow 2 \mathrm{H}_{2} \mathrm{O}
\end{gathered}
$$

A wide variety of sensors have been used for direct-reduction of $\mathrm{O}_{2}$ with the majority of measurements obtained using constant potential amperometry (CPA) at a noble metal microelectrode such gold ${ }^{5}$ or platinum. ${ }^{6}$ The use of carbon-based electrodes has been reported by several groups ${ }^{7-9}$ and often they are preferred to Pt cathodes because of their in vivo stability and less surface poisoning. ${ }^{9}$ Moreover, $10 \mu \mathrm{m}$ Nafion-coated carbon fibers, coupled with fast scan voltammetry (FCV), have been used for the measurement of dissolved oxygen with a subsecond time resolution. ${ }^{8}$ However, as previously discussed, ${ }^{9}$ the ideal sensor size has to be greater than the dimension of blood capillaries $(\sim 100 \mu \mathrm{m})$ for preventing direct blood sampling of dissolved oxygen. In this article we present a new oxygen sensor geometry (conical) particularly suited for in vivo applications, minimizing the tissue trauma related to the stereotaxic implantation of the sensor in specific brain regions for recording in freely moving rats.

(4) Southampton Electrochemistry Group. Instrumental Methods in Electrochemistry, 1st ed.; Ellis Horwood: Chichester-West Sussex, U.K., 1985.

(5) Holmstrom, N.; Nilsson, P.; Carlsten, J.; Bowald, S. Biosens. Bioelectron. 1998, 13, 1287-1295.

(6) Ward, W. K.; Wood, M. D.; Slobodzian, E. P. J. Med. Eng. Technol. 2002, $26,158-167$.

(7) Lowry, J. P.; Boutelle, M. G.; O’Neill, R. D.; Fillenz, M. Analyst 1996, 121, 761-766.

(8) Venton, B. J.; Michael, D. J.; Wightman, R. M. J. Neurochem. 2003, 84, 373-381.

(9) Bolger, F. B.; Lowry, J. P. Sensors 2005, 5, 473-487. 
In recent years, sophisticated telemetry systems have been developed for monitoring neurochemicals, such as brain dopamine, in freely moving animals. ${ }^{10,11}$ However, only a few systems ${ }^{12}$ have been sufficiently miniaturized and are thus light enough to be implanted in small rodents. None of these systems have been designed for the exclusive monitoring of brain oxygen. In this paper we describe a miniaturized biotelemetric device, specifically suited to work with $\mathrm{O}_{2}$-reduction sensors, successfully used for the in situ detection of dissolved oxygen in brain extracellular fluid (ECF) of freely moving rats. The proposed system can serve as a rapid and reliable model for studying the effects of physiological stimulation or different drugs on brain oxygen and cerebral blood flow.

\section{EXPERIMENTAL SECTION}

Reagents and Solutions. All chemicals were analytical reagent grade, used as supplied, and dissolved in bidistilled deionized water (MilliQ). Acetazolamide (Sigma, ref A6011), graphite powder (Fluka, ref 78391) and collodion solution (4\% cellulose nitrate in ethanol/diethyl ether from Fluka, ref 09986) were purchased from Sigma-Aldrich (Milano, Italy). The phosphatebuffer saline (PBS) solution was made using $\mathrm{NaCl}(137 \mathrm{mM}), \mathrm{KCl}$ (2.7 mM), $\mathrm{Na}_{2} \mathrm{HPO}_{4}(8.1 \mathrm{mM})$, and $\mathrm{KH}_{2} \mathrm{PO}_{4}(1.47 \mathrm{mM})$ from Sigma, then adjusted to $\mathrm{pH}$ 7.4. Ultrapure (>99.9\%) oxygen and nitrogen were purchased from Sapio s.r.1 Special Gases Division (Caponago, Italy). $\mathrm{N}_{2}$-purged and $\mathrm{O}_{2}$-saturated solutions, used for in vitro calibrations at low concentrations, were prepared by dissolving (bubbling) the appropriate gas in $10 \mathrm{~mL}$ of PBS for $1 \mathrm{~h}$. The air-saturated solution of PBS $\left(21 \% \mathrm{O}_{2}\right)$ was prepared by bubbling filtered air in $10 \mathrm{~mL}$ of PBS for $1 \mathrm{~h}$, using a diaphragm air pump (DAP). All in vitro calibrations were performed in freshly prepared $\mathrm{N}_{2}$ and $\mathrm{O}_{2}$ solutions under standard conditions of pressure and temperature.

Materials and Electronic Parts. Electronic parts and plastic enclosures were from Farnell-In-One spa (Milano, Italy), the radio modules were from Telecontrolli spa (TC, Casoria, Italy), and the USB components were preassembled by Futura Elettronica srl (Gallarate, Italy). The amperometric section of the biotelemetric device was built using a dual single-supply operational amplifier MCP6042 (Arizona Microchip, Chandler) and a ZXRE4001 zener diode (Zetex, Manchester, U.K.). The analog-to-digital converter (ADC) was an integral part of the microcontroller (PIC12F683, Arizona Microchip) used in this system. The $433.92 \mathrm{MHz}$ amplitude modulation (AM) transmitter was a RT4-433.92 (TC) while the RR3-433.92 module (TC) was selected as the AM receiver. Both TC modules were equipped with external antennas. The serial-to-universal serial bus (USB) converter was a FTDIFT232R module with internal E2PROM and integrated clock synthesizer. All resistors were precision metal oxide thick film (250 mW, 0.1\% tolerance, Ohmite, Rolling Meadows, IL). All capacitors were NP0-type multilayer ceramic (low pass filter, decoupling) or electrolytic (decoupling). The components were

(10) Crespi, F.; Dalessandro, D.; Annovazzi-Lodi, V.; Heidbreder, C.; Norgia, M. J. Neurosci. Methods 2004, 140, 153-161.

(11) Garris, P. A.; Ensman, R.; Poehlman, J.; Alexander, A.; Langley, P. E.; Sandberg, S. G.; Greco, P. G.; Wightman, R. M.; Rebec, G. V. J. Neurosci. Methods 2004, 140, 103-115.

(12) Morita, H.; Abe, C.; Awazu, C.; Tanaka, K. Neurosci. Lett. 2007, 412, 201205. soldered on single side printed circuit boards (PCB) produced as previously described. ${ }^{13,14}$ Emilac, Positiv, and Plastic technical sprays were from Cramolin (Mühlacker, Germany). All electronic parts used in this project were $\mathrm{Pb}$-free and compliant to RoHS directives. A detailed description of the biotelemetric device, weighing only $9.6 \mathrm{~g}$, is provided in the Supporting Information.

Animals. Male Sprague-Dawley rats (Morini R. Emilia, Italy), weighing 280-330 g, were used for in vivo experiments. The rats were maintained under standard animal care conditions $(12 \mathrm{~h} / 12$ $\mathrm{h}$ light/dark cycle, light at $07.00 \mathrm{~h}$; room temperature $21^{\circ} \mathrm{C}$ ), with food and water ad libitum. Prior to the start of any experimental procedure, the health of the animals was assessed according to published guidelines. ${ }^{15}$ All procedures were specifically licensed under the European Community directive 86/609 included in Decreto No. 116/1992 of the Italian Ministry of Public Health.

Preparation and Calibration of Oxygen Microsensors. The $\mathrm{O}_{2}$ microsensors were made using Teflon-insulated silver wires (30 mm in length; i.d. $=125 \mu \mathrm{m}$, Advent Research Materials, Suffolk, U.K.) modifying a previously described procedure. ${ }^{16}$ Approximately $1 \mathrm{~mm}$ of the wire was exposed and inserted into a silica capillary tube $(10 \mathrm{~mm}$ in length; i.d. $=180 \mu \mathrm{m}$, Polymicro Technologies, Phoenix, AZ) partly filled with graphiteloaded (55\% w/w) epoxy resin (Araldite-M, Sigma-Aldrich, Milan, Italy). A preliminary $180 \mu \mathrm{m}$ diameter carbon-composite disk electrode (area, $2.5 \times 10^{-4} \mathrm{~cm}^{2}$ ) was fabricated by mixing $850 \mathrm{mg}$ of graphite with $500 \mathrm{mg}$ of Araldite-M and $200 \mathrm{mg}$ of harderer ${ }^{16}$ and filling the silica capillary tubing with the mixture. The silver wire guaranteed a good electrical contact. After $24 \mathrm{~h}$ at $40{ }^{\circ} \mathrm{C}$, the shape of the working electrode (WE) was transformed from circular to conical (Figure 1A) using a high speed drill (Dremel 300) equipped with an aluminum oxide grinding wheel. The final $\mathrm{O}_{2}$ microsensors had a length $\approx 250$ $\mu \mathrm{m}$, a surface $\approx 1.5 \times 10^{-3} \mathrm{~cm}^{2}$, and a tip $<25 \mu \mathrm{m}$, dimensions well below those associated with significant tissue trauma caused by the implantation of larger probes. ${ }^{17,18}$ Cellulose nitrate treatment was performed by immersing the WE in the collodion solution three times and drying it for $60 \mathrm{~min}$ after each coat at 40 ${ }^{\circ} \mathrm{C}$. $\mathrm{O}_{2}$ reduction was experimentally demonstrated on the microsensor surface (Figure $1 \mathrm{~B}$ ) starting from $-350 \mathrm{mV}$ vs $\mathrm{Ag}$ / $\mathrm{AgCl}$, using cyclic voltammetry (CV37 voltammograph, BAS, Bioanalytical Systems Inc., West Lafayette) with a scan rate of 25 $\mathrm{mV} / \mathrm{s}$. Constant potential amperometry (CPA) was used for in vitro and in vivo calibrations and experiments, fixing the $\mathrm{O}_{2}$ reduction potential at $-400 \mathrm{mV}$ vs $\mathrm{Ag} / \mathrm{AgCl}$ reference electrode. No significant interference signals were observed on exposing the sensors to other electroactive molecules (ascorbic acid (AA); uric acid (UA); dopamine (DA); 3,4-dihydroxy-phenylacetic acid (DOPAC); homovanillic acid (HVA)) present in the striatal

(13) Serra, P. A.; Rocchitta, G.; Bazzu, G.; Manca, A.; Puggioni, G. M.; Lowry, J. P.; O’Neill, R. D. Sens. Actuators, B: Chem. 2007, 1, 118-126.

(14) Rocchitta, G.; Migheli, R.; Dedola, S.; Calia, G.; Desole, M. S.; Miele, E.; Lowry, J. P.; O’Neill, R. D.; Serra, P. A. Sens. Actuators, B: Chem. 2007, 126, 700-709.

(15) Wolfensohn, S.; Lloyd, M. Handbook of Laboratory Animal Management and Welfare, 3rd ed.; Blackwell Publishing: Oxford, U.K., 2003.

(16) Migheli, R.; Puggioni, G.; Dedola, S.; Rocchitta, G.; Calia, G.; Bazzu, G.; Esposito, G.; Lowry, J. P.; O’Neill, R. D.; Desole, M. S.; Miele, E.; Serra, P. A. Anal. Biochem. 2008, 380, 323-330.

(17) Duff, A.; O’Neill, R. D. J. Neurochem. 1994, 62, 1496-1502.

(18) Fumero, B.; Guadalupe, T.; Valladares, F.; Mora, F.; O’Neill, R. D.; Mas, M.; Gonzalez-Mora, J. L. J. Neurochem. 1994, 63, 1407-1415. 

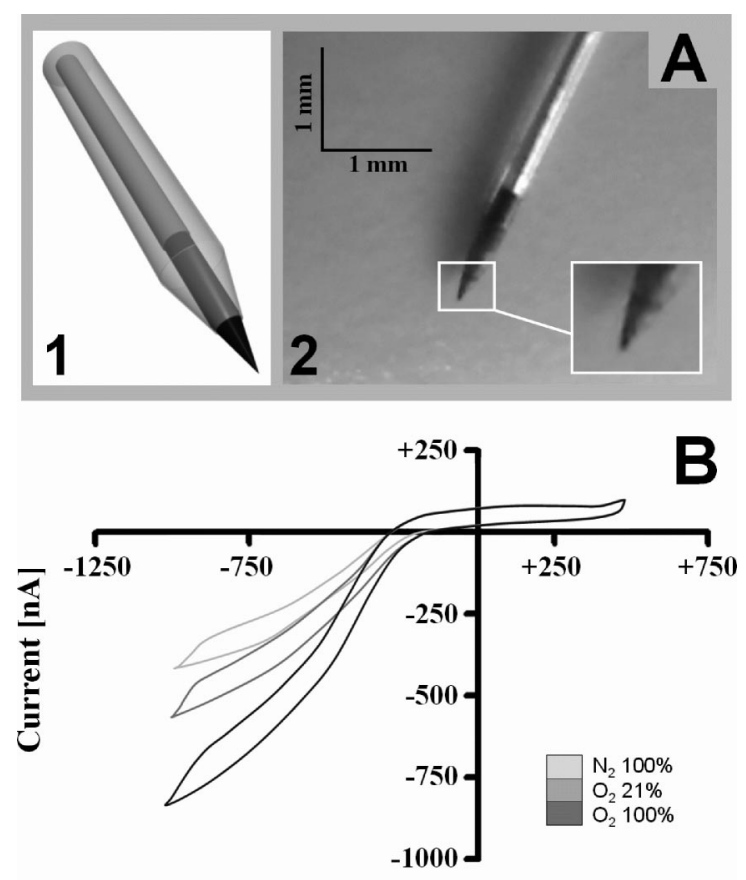

Applied potential $[\mathrm{mV}]$

Figure 1. Schematic (A1) and microphotograph (A2) of the conical oxygen microsensor developed and used in this study and its electrochemical characterization (B) using cyclic voltammetry (CV). The conical shape (A2, inset) reduces brain trauma related to the stereotaxic implantation. CV shows the sensor response to $\mathrm{O}_{2}$, starting from $-350 \mathrm{mV}$ vs $\mathrm{Ag} / \mathrm{AgCl}$, similar to that obtained on glassy carbon electrodes suggestive of two-step $\mathrm{O}_{2}$ reduction (see text).

extracellular fluid, even at pharmacologically relevant concentrations $(0.5 \mathrm{mM}$ for $\mathrm{AA}$ and up to $5 \mu \mathrm{M}$ for the other neurochemicals). ${ }^{16}$

Sensor selection was performed connecting microelectrodes to a three-electrode system (BAS CV37) and exposing them to variable $\mathrm{O}_{2}$ concentrations $(0 \%-100 \%)$ by means of the apparatus illustrated in Figure 2; only sensors having a $\mathrm{O}_{2}$ sensitivity higher than $200 \mathrm{pA} \mu \mathrm{M}^{-1}$ were selected (Figure 3A). A more accurate calibration was performed at low oxygen concentrations (Figure 3B) connecting the microsensor to the biotelemetric device (two-electrode system) and adding known volumes of a standard $\mathrm{O}_{2}$ solution (100\%) to nitrogen-saturated PBS. Only WEs having an $\mathrm{O}_{2}$ detection limit $\leq 5 \mu \mathrm{M}$ were selected for in vivo implantation. The $\mathrm{Ag} / \mathrm{AgCl}$ reference/ auxillary (ref/aux) electrode, connected to the biotelemetric device, was prepared by immersing $1 \mathrm{~mm}$ silver wire (i.d. $=$ $125 \mu \mathrm{m})$ in a saturated $\mathrm{KCl}$ solution and applying $+500 \mathrm{mV}$ for $1 \mathrm{~min}$.

Stereotaxic Surgery and in Vivo Experimental Procedures. Stereotaxic surgery was performed under chloral hydrate (400 $\mathrm{mg} \mathrm{kg}{ }^{-1}$ i.p.) anesthesia. The oxygen microsensor was implanted in the right striatum using the following coordinates from the atlas of Paxinos and Watson: ${ }^{19} \mathrm{~A} / \mathrm{P}+0.5$ from the bregma, $+2.5 \mathrm{M} / \mathrm{L}$, and $-4.0 \mathrm{D} / \mathrm{V}$ from the dura. The ref/aux electrode was implanted in the left parietal cortex, and two screws were inserted in the skull for reinforcing the biotelemetric device adhesion. The "basement" portion of the device

(19) Paxinos, G.; Watson, C. The Rat Brain in Stereotaxic Coordinates, 6th ed.; Academic Press: San Diego, CA, 2007.

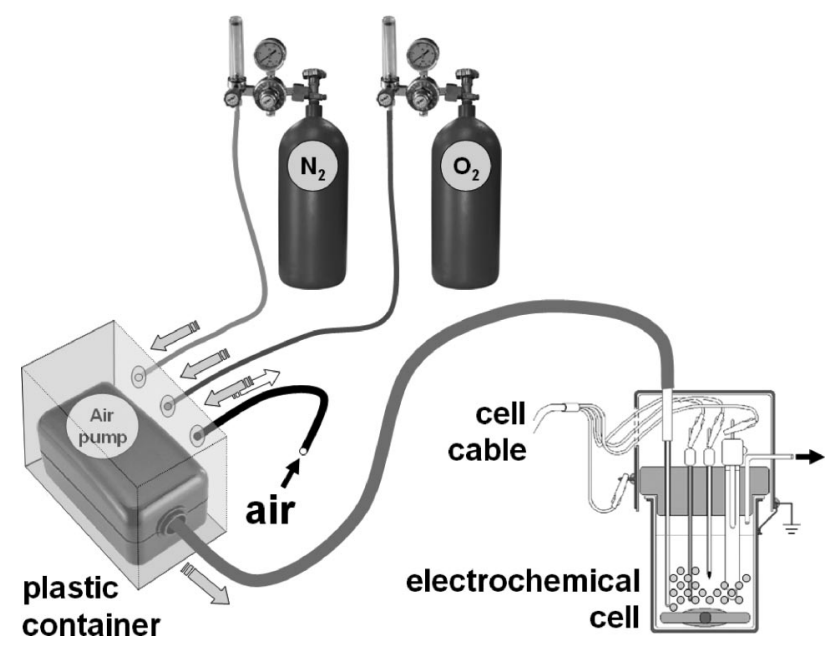

Figure 2. Drawing of the apparatus for calibrating microsensors using high $\mathrm{O}_{2}$ concentrations. Pure gas cylinders were connected to a plastic container enclosing a diaphragm air pump (DAP). During DAP operation, when a gas cylinder is open, the "air" access serves as an overpressure valve (output). When the gas cylinders are closed, the plastic container is rapidly saturated with air $\left(\mathrm{O}_{2} 21 \%\right) . \mathrm{N}_{2}$ and $\mathrm{O}_{2}$ cylinders were alternatively opened while DAP transferred the content of the plastic container in the electrochemical cell (bubbling). The main aim of this equipment is to obtain a constant gas flow-rate and a homogeneous electrochemical signal which is independent of noise from the opening/closing of gas cylinders during gas bubbling.

(without battery) was fixed to the skull using dental cement (Paladur, Heraeus Kulzer, GmbH), and the electrodes were connected and the skin was sutured (Figure 4A). A "dummy cover" was coupled to the "basement" to prevent its fouling. Body temperature during anesthesia was maintained at $37^{\circ} \mathrm{C}$ by means of an isothermal heating pad. After surgery (Figure 4B), the animals were housed in large plastic bowls ( $45 \mathrm{~cm}$ diameter) and maintained in a temperature- and light-controlled environment, with free access to food and water. The $\mathrm{O}_{2}$ microsensor was polarized $24 \mathrm{~h}$ after surgery (day 1 ) substituting the "dummy cover" with a "real cover", after the insertion of the battery in the "basement". The oxygen monitoring started with the animal in its home bowl: this arrangement allowed the rat free movement (Figure $4 \mathrm{C}$ ). Following the procedure previously described in detail, ${ }^{9}$ mild hyperoxia and hypoxia were induced on day 1 exposing the rat for $5 \mathrm{~min}$ to $\mathrm{O}_{2}$ and $\mathrm{N}_{2}$, respectively. Acetazolamide was administered i.p. $\left(50 \mathrm{mg} \mathrm{kg}^{-1}\right) 48 \mathrm{~h}$ after microsensor implantation (day 2). Physiological stimulations (tail pinch and induced grooming) were carried out within the first week after stereotaxic surgery (Figure 4).

Histology. Following the experiments (day 8), rats were sacrificed with an overdose of chloral hydrate $\left(800 \mathrm{mg} \mathrm{kg}^{-1}\right.$ i.p.). The location of each oxygen microsensor was confirmed by postmortem histology. Brains were fixed in formal saline, and $50 \mathrm{~mm}$ coronal sections were made with a cryostat. The slices were stained with cresyl violet and examined under a microscope.

Statistical Analysis. Concentrations of dissolved $\mathrm{O}_{2}$ were expressed in micromolar while oxygen reduction current was expressed in nanoamps and given as baseline-subtracted (Delta $-I)$ raw data or the mean of 50-1800 consecutive recordings \pm standard error of the mean (SEM). The sign of the oxygen 

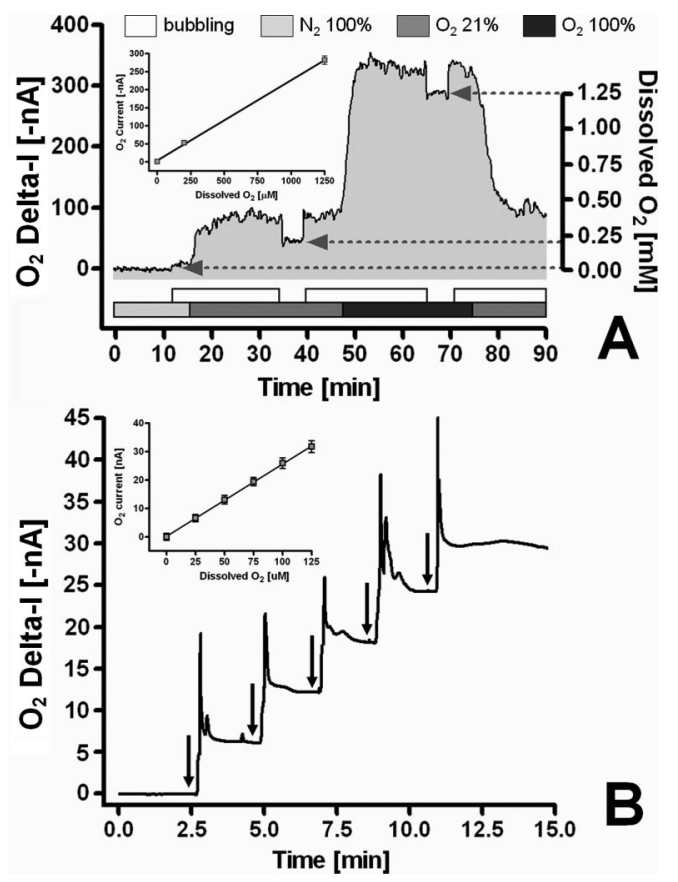

Figure 3. In vitro calibrations of oxygen microsensors using high (A) and low (B) $\mathrm{O}_{2}$ concentrations. Constant potential amperometry was performed at $-400 \mathrm{mV}$ vs $\mathrm{Ag} / \mathrm{AgCl}$ reference electrode and the sensors response to $\mathrm{O}_{2}$ was tested by first exposing them to increasing $\mathrm{O}_{2}$ concentrations $(0,0.2$, and $1.25 \mathrm{mM})$ by means of the apparatus illustrated in Figure 2. Baseline-subtracted currents (Delta - I) were recorded in quiescent conditions a few minutes after stopping the DAP. Only sensors having $\mathrm{O}_{2}$ sensitivity higher than $200 \mathrm{pA} \mu \mathrm{M}^{-1}$ were selected (panel $A$, inset). A more accurate calibration (panel $B$, inset) was performed at low oxygen concentrations connecting the microsensor to the biotelemetric device and adding known volumes $(+200,+204,+208,+212$, and $+216 \mu \mathrm{L})$ of a saturated $\mathrm{O}_{2}$ solution $(1.25 \mathrm{mM})$ to $10 \mathrm{~mL}$ of nitrogen-saturated PBS.

currents was inverted for improving the readability of the plotted data. After in vitro calibrations, the oxygen current was plotted vs the $\mathrm{O}_{2}$ concentration and the linear regression was calculated. The changes of brain tissue $\mathrm{O}_{2}$ were calculated as absolute variations versus the corresponding baseline, and the oxygen concentrations were estimated (in micromolar) using pre- and postimplantation in vitro calibrations. The statistical significance of changes was evaluated using paired $t$ tests between the means of consecutive recordings before (baseline) and during the maximum magnitude of oxygen changes as a result of physiological stimulations or pharmacological treatments.

\section{RESULTS}

Electronics Test and Calibration. An automated dummy cell was made based on a previously published design ${ }^{13}$ for testing the amperometric module of the biotelemetric device before sensor calibration. The aim of the design was to devise a Thevenin current source that would reproduce the constant amperometric response of a true electrochemical cell. The dummy cell was assembled connecting five resistors (100, 50, 20,10, and 6.7 M $\Omega$ ) to a multiposition switch and soldering together the resistors' free terminals. The voltage applied to the dummy cell was generated between the $\mathrm{WE}$ and the ref/aux electrodes and is equal to the voltage difference between the above electrodes $(-400 \mathrm{mV})$; the resulting cathodic currents $(-4,-8,-20,-40$, and $-60 \mathrm{nA})$ were converted in an output voltage $\left(V_{\text {Out }}\right)$ as illustrated in the
Supporting Information. The calibration was made indoors with a linear distance between the TX and RX units of about $3 \mathrm{~m}$. The baseline was recorded for 7 consecutive days of continuous operation, and a 5-point calibration was performed daily. After the operations described above, a $-20 \mathrm{nA}$ current was generated though the dummy cell by setting the dummy cell resistor to 20 $\mathrm{M} \Omega$. The system was left under these conditions until the next calibration, which was made the following day. A maximum $V_{\text {out }}$ shift of $5 \mathrm{mV}$ was observed overnight while the current related to electronic noise was around $20 \mathrm{pA}$. At the end of the week, the values of $V_{\text {Out }}$ were plotted versus the theorical values of the correspondent currents (data not shown), and linear regression was calculated (slope $=-10.13 \pm 0.04 \mathrm{mV} \mathrm{nA}^{-1} ; r^{2}$ $=0.999 ; n=7)$. Power consumption results are provided in the Supporting Information.

Microsensor Response to Oxygen. All in vitro calibrations were performed $24 \mathrm{~h}$ after microsensor manufacture, the same day of the in vivo implantation (day 0 , precalibration), and repeated 8 days later, after the rat sacrifice (day 8, postcalibration). A 10 $\mathrm{mL}$ Teflon beaker was modified as described in a previous paper ${ }^{13}$ and used for calibrations (Figure 2). The sensor response to high $\mathrm{O}_{2}$ concentrations was tested in quiescent conditions, connecting the WE to a BAS CV37 voltammograph and using the apparatus and the procedure illustrated in Figures 2 and $3 \mathrm{~A}$. The precalibration (Figure 3A, inset) displayed good linearity with a slope of $222 \pm 17 \mathrm{pA} \mu \mathrm{M}^{-1}$ of $\mathrm{O}_{2}\left(r^{2}=0.992 ; n=6\right)$, while the postcalibration (data not shown) revealed a small reduction in linearity and sensitivity $(-18 \%)$ and an increase in dispersion (slope $=183 \pm 14 \mathrm{pA} \mu \mathrm{M}^{-1}, r^{2}=0.981$ ). Before the calibration procedure using low $\mathrm{O}_{2}$ concentrations, the oxygen microsensor was connected to the biotelemetry device and placed in the beaker containing nitrogen-saturated PBS. A constant potential of $-400 \mathrm{mV}$ vs $\mathrm{Ag} / \mathrm{AgCl}$ was applied, and the calibration apparatus was placed on a stirrer until a stable baseline was reached ( $15 \pm 5 \mathrm{nA}$ on day 0 and $12 \pm 6 \mathrm{nA}$ on day 8). A $20 \mathrm{~mm}$ diameter magnetic bar was used to mix the solution after each addition of $\mathrm{O}_{2}$-saturated PBS solution (Figure $3 \mathrm{~A}$ ), and the $\mathrm{O}_{2}$ reduction current was recorded under quiescent conditions after stirring. The precalibration (Figure $3 \mathrm{~B}$, inset) displayed good linearity with a slope of $255 \pm 22 \mathrm{pA}$ $\mu \mathrm{M}^{-1}$ of $\mathrm{O}_{2}\left(r^{2}=0.999 ; n=6\right)$ while the postcalibration (data not shown) revealed a reduction in sensitivity comparable with that previously reported using high $\mathrm{O}_{2}$ concentrations. The response time of sensors was $<1 \mathrm{~s}$. For a detailed description of the calibration procedures, refer to legends of Figures 2 and 3.

Baseline Levels of Striatal $\mathrm{O}_{2}$. Baseline striatal currents were recorded daily starting from day 1 . The initial microsensor stabilization was obtained after a period of $47 \pm 19 \min (n=6)$ following the activation of the system as previously described. A total of 30 min of raw data, consisting of 1800 consecutive current measurements, were recorded in the morning immediately before physiological or pharmacological testing, averaged, and evaluated together as mean $\pm \operatorname{SEM}(n=42)$. The calculated oxygen baseline current was $22 \pm 4 \mathrm{nA}$. Considering that the averaged background current of the microsensor in nitrogen-saturated PBS (days 0 and 8) was around $14 \mathrm{nA}$, it is possible to estimate the concentration of $\mathrm{O}_{2}$ using in vitro pre- and postcalibrations; this was found to 

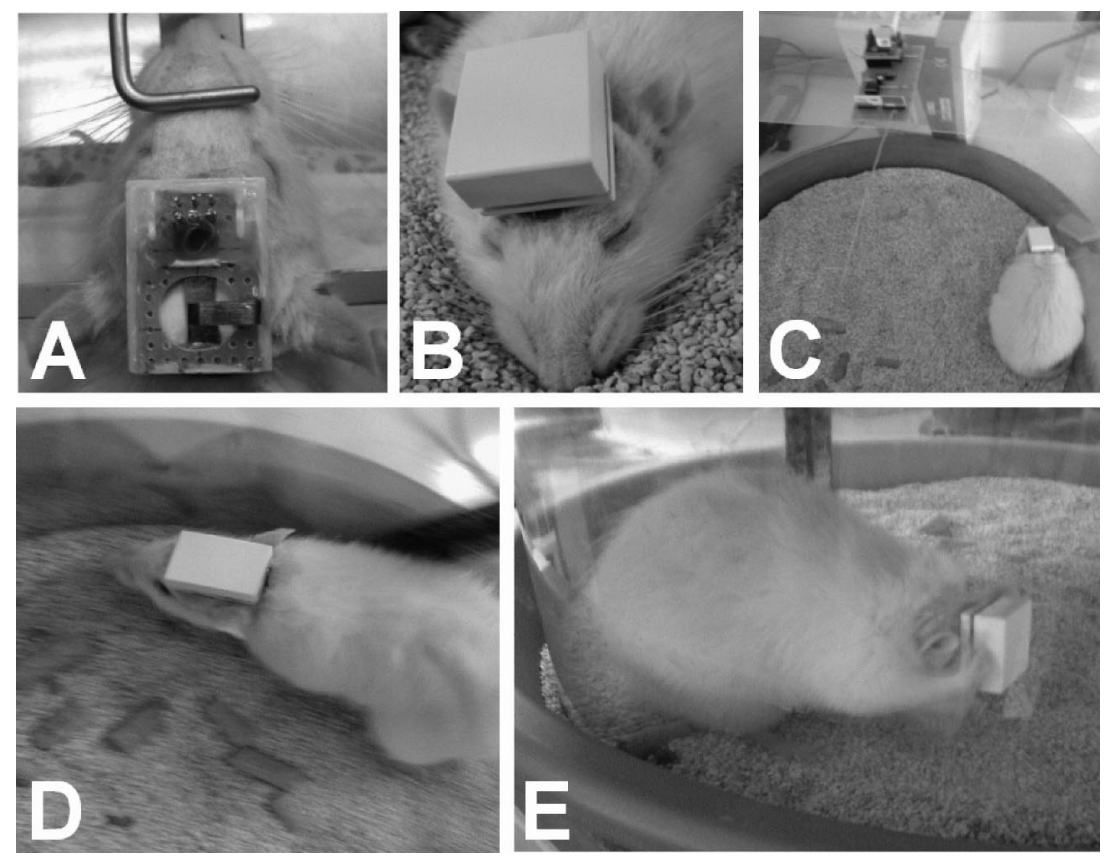

Figure 4. In vivo experimental procedures for validating the biotelemetric system design. The "basement" portion of the device was fixed to the skull using dental cement, (A) and a "dummy cover" (B) was coupled to the "basement" to prevent its fouling. Following surgery, the animals were housed in large plastic bowls and maintained in a temperature- and light-controlled environment, with free access to food and water (C). The oxygen monitoring started $24 \mathrm{~h}$ after surgery. Pharmacological treatments and physiological stimulations such as tail pinch (D) and induced grooming (E) were carried out within the first week after stereotaxic surgery.

correspond to $37 \pm 16 \mu \mathrm{M}$, a value consistent with previous estimates. ${ }^{20-22}$ Fluctuations in baseline levels were observed day by day and within the same day, mainly related to the activity of the rat (data not shown), as reported previously. ${ }^{1,7}$

Effect of Physiological Stimulation on Striatal $\mathrm{O}_{2}$ Current. Physiological stimuli, chosen to increase neural activity and regional cerebral blood flow $(\mathrm{rCBF})$, were administered in the form of a tail pinch or a water spray. A 5 min tail pinch was applied to freely moving rats $(n=6)$ resulting in the oxygen changes illustrated in Figure 5A; a few seconds after the paper clip application we observed an enhancement in motor and chewing activities (Figure 4D) and a significant increase in striatal $\mathrm{O}_{2}$ current $(2.9 \pm 0.6 \mathrm{nA}, p<0.05)$ estimated as $+12.4 \pm 2.4 \mu \mathrm{M}$. Stimulated water-induced grooming activity (Figure $4 \mathrm{E}$ ) was evoked by misting rats with water and resulted in a statistically significant increase of striatal $\mathrm{O}_{2}$ current compared to the previous baseline level ( $2.76 \pm 0.31 \mathrm{nA}, p<0.01)$, as shown in Figure 5B. The extrapolated increase in $\mathrm{O}_{2}$ concentration was calculated as $12.0 \pm 1.3 \mu \mathrm{M}$ using in vitro postcalibration curves.

Effect of $\mathrm{O}_{2}$ and $\mathrm{N}_{2}$ Administration on Striatal $\mathrm{O}_{2}$ Current. Pure oxygen and nitrogen were administered to the rat, housed in its own bowl covered with a $50 \mathrm{~cm}$ plexiglas disk, by connecting the pure gas cylinders directly to the bowl and opening them alternatively at high fluxes $(2 \mathrm{~L} / \mathrm{min})$. In this manner, the gas saturated the bowl in a few seconds and the animal was forced to breath a mixture of air $-\mathrm{O}_{2}$ or air $-\mathrm{N}_{2}$ for 5 min, as illustrated in Figure 6A. Between $\mathrm{O}_{2}$ and $\mathrm{N}_{2}$ treatments, the bowl was ventilated for quick removal of gas residuals.

(20) Zauner, A.; Bullock, R.; Di, X.; Young, H. F. Neurosurgery 1995, 37, 11681176.

(21) Murr, R.; Berger, S.; Schuerer, L.; Peter, K.; Baethmann, A. Pflugers Arch. 1994, 426, 348-350.

(22) Nair, P. K.; Buerk, D. G.; Halsey, J. H., Jr. Stroke 1987, 18, 616-622.
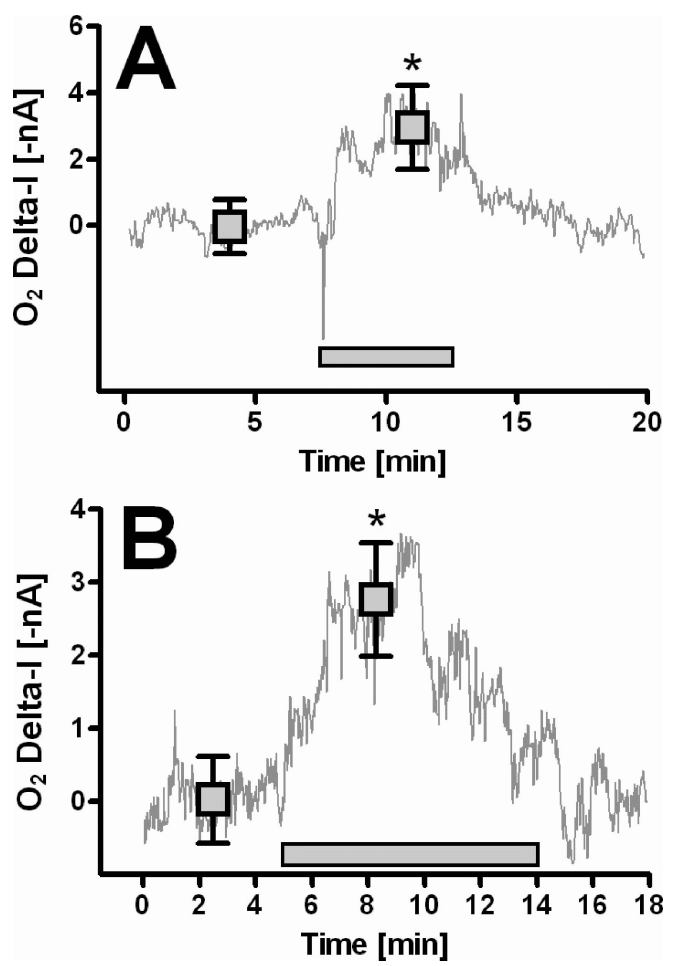

Figure 5. Effect of physiological stimulation on striatal dissolved oxygen. A 5 min tail pinch was applied to freely moving rats $(A)$ resulting in an enhancement in motor and chewing activities observed a few seconds after the paper clip application with a concomitant increase in striatal $\mathrm{O}_{2}$ current $\left(+2.9 \pm 0.6 \mathrm{nA},{ }^{*}, p<0.05\right.$ vs baseline). Induced grooming $(B)$ was evoked by misting rats with water and resulted in a statistically significant increase of striatal $\mathrm{O}_{2}$ signal $(+2.76 \pm 0.31 \mathrm{nA}$, *, $p<0.01$ vs baseline). Delta $-I$, baseline-subtracted current.

Upon exposure of the animals to pure oxygen, the striatal $\mathrm{O}_{2}$ current promptly increased by $+8.5 \pm 1.3 \mathrm{nA}(+37 \pm 6 \mu \mathrm{M})$, 

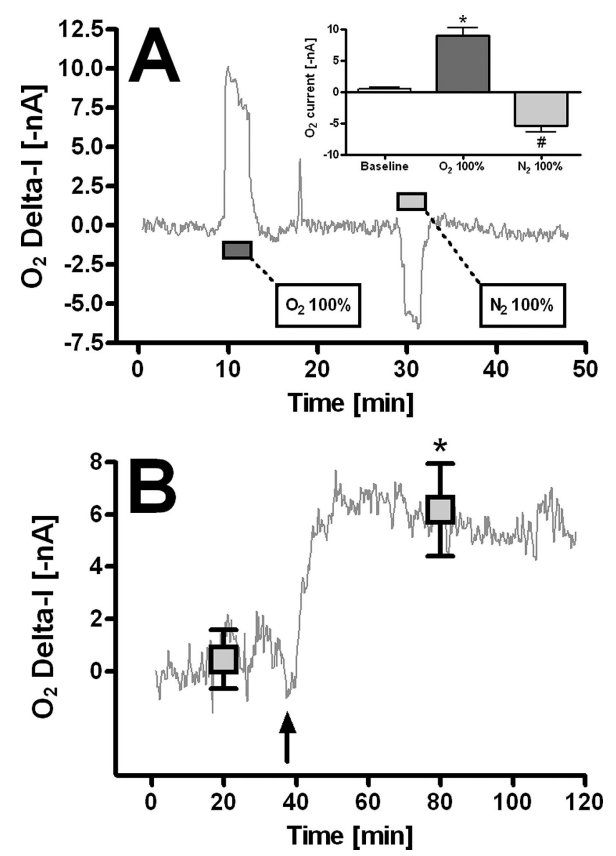

Figure 6. Effect of pharmacological treatments on striatal dissolved oxygen. Exposing the animal to pure oxygen $(A)$, the striatal $\mathrm{O}_{2}$ current promptly increased by $+8.5 \pm 1.3 \mathrm{nA}\left({ }^{*}, p<0.01\right.$ vs baseline) returning-back to baseline immediately after $\mathrm{O}_{2}$ removal. On the contrary, the exposure to nitrogen $(A)$ induced a short-lasting decline of the striatal oxygen signal ( $-5.8 \pm 1.0 \mathrm{nA} ; \#, p<0.01$ vs baseline). Acetazolamide, a carbonic anhydrase inhibitor, was administered $i$. p. at the dosage of $50 \mathrm{mg} \mathrm{kg}^{-1}$. An increase of striatal $\mathrm{O}_{2}$ current was observed during the first minutes after acetazolamide administration $(B)$ and remained high for several hours. The maximum oxygen variation vs baseline $\left(+5.7 \pm 0.7 \mathrm{nA} ;{ }^{*}, p<0.05\right)$ was achieved 20-40 min after the drug injection. Delta $-I$, baseline-subtracted current.

returning to baseline immediately after $\mathrm{O}_{2}$ removal. In contrast, the exposure to nitrogen induced a short-lasting decline of the striatal oxygen signal $(-5.8 \pm 1.0 \mathrm{nA})$, estimated as $-23 \pm 4$ $\mu \mathrm{M}$ from the baseline. Both striatal changes were statistically different from the baseline (Figure 6A, top-right inset; ${ }^{*}, p<$ 0.05).

Effect of Systemic Acetazolamide Administration on Striatal $\mathrm{O}_{2}$ Current. The carbonic anhydrase inhibitor acetazolamide (Diamox) is a drug that induces a rise in brain oxygen. ${ }^{23}$ The drug was dissolved in $1.5 \mathrm{~mL}$ of saline and administered i. p. at the dose of $50 \mathrm{mg} \mathrm{kg}^{-1}$. An increase in striatal $\mathrm{O}_{2}$ current was observed during the first minutes after acetazolamide administration (Figure 6B) and remained high for several hours. The maximum oxygen variation vs baseline $\left({ }^{*}, p<0.05\right)$ was achieved $20-40 \mathrm{~min}$ after the drug injection with an increase of $+5.7 \pm 0.7$ $\mathrm{nA}$, corresponding to $+25 \pm 3 \mu \mathrm{M}$ of $\mathrm{O}_{2}$. A control group of animals received only saline (data not shown) resulting in a short-lasting increase of striatal oxygen, in agreement with previously published observations related to mild stress. ${ }^{9}$

\section{DISCUSSION}

Principles of Operation and Performance of the Biotelemetric Device. The analog circuitry of the biotelemetric device was optimized for single-supply, low-voltage operation, using a

(23) Rivera-Ch, M.; Huicho, L.; Bouchet, P.; Richalet, J. P.; Leon-Velarde, F. Respir. Physiol. Neurobiol. 2008, 162, 184-189. single stage of amplification and reducing the number of electronic components. The amperometric module is build around $V_{z}$, a fixed voltage $(1.22 \mathrm{~V})$ generated by an ultralow-power zener diode. $V_{\text {ref/aux }}$ was directly connected to $V_{z}$ while the WE was stabilized to $820 \mathrm{mV}\left(-400 \mathrm{mV}\right.$ vs $\left.V_{z}\right)$ by means of a buffered voltage divider. As shown in the Supporting Information (Figure S-1A), fixing $R_{\mathrm{f}}$ to $10 \mathrm{M} \Omega, \mathrm{OPA}_{2}$ converted the input reduction current to $V_{\text {Out }}$ with an amplification factor of $100 \mathrm{nA} / \mathrm{V}$. In this manner we successfully overcame the limitations of the previous design ${ }^{13,14}$ related to variations in the resistor values, mainly in the difference circuit. In fact we completely suppress the differentiator by transferring to firmware the $V_{\mathrm{App}}$-subtraction previously implemented by hardware. The $\mathrm{ADC}$ input of the microcontroller was directly wired to $V_{\text {Out }}$ and the $\mathrm{ADC}$ reference connected to $V_{\mathrm{z}}$. This means that $V_{\text {Out }}$ was digitized in a range between 0 and $1.22 \mathrm{~V}$ with an oversampled resolution of 14 bits (corresponding to 16384 least significant bits (LSBs). The digital value 11012 corresponds to $820 \mathrm{mV}$ (0 nA) while 5640 to $420 \mathrm{mV}(-40 \mathrm{nA})$ and so on. The micro controller unit (MCU) performed the specific conversion for obtaining the current values (inverted in sign) and transmitted them to the receiver. $V_{\mathrm{App}}$ could be modified by changing the values of $R_{1}$ and $R_{2}$ (Supporting Information, Figure S-1A) or substituting them with a trimmer potentiometer; in this case it is important to consider that lowering $V_{\mathrm{App}}$ reduces the range of the input current. The input current range could be (re)extended decreasing the value of $R_{\mathrm{f}}$. The main advantage of the described electronics is that $V_{\mathrm{Z}}$ and $V_{\mathrm{App}}$ are independent from the voltage drop related to battery discharge. The result is that the module is characterized by gain precision, stability, and an excellent linear response. The system can operate only in reduction mode, and it is particularly suited to work with direct-reduction sensors, such oxygen microsensors, or $\mathrm{O}_{2}$-consuming biosensors based on oxidase enzymes. ${ }^{24}$ The power consumption lower than $400 \mu \mathrm{W}$ guarantees a long battery life. The biotelemetric system was interfaced to the software via USB with the possibility of high-level access to the received packets. This means that further data handling could be done by means of widely used software packages such as LabView or Dasylab. All experiments were made indoor, in a linear range comprised between 0 and $3 \mathrm{~m}$, without communication problems. The weight of the implantable biotelemetry unit is compatible with similar commercial devices, ${ }^{12}$ represents $\sim 3 \%$ of the rat body weight, and it is well tolerated by the animals in agreement with other studies. ${ }^{25}$ The operation of several biotelemetric systems, operating in the same room, was tested after reduction of the transmission distance by varying the antenna tuning and modifying the "synch" byte of the transmission packet.

Performance of the Oxygen Microsensor. Oxygen microsensors were developed using an original procedure for obtaining carbon-epoxy cone electrodes optimized for in vivo applications. The conical shape reduces tissue trauma related to the stereotaxic implantation in the striatum while the size, ranging from $\sim 25$ (cone tip) to $180 \mu \mathrm{m}$ (cone base), guarantees oxygen detection in brain tissue and not in small blood vessels as reported for carbon fibers. ${ }^{9}$ The electrode surfaced was coated with

(24) Wu, L.; Zhang, X.; Ju, H. Biosens. Bioelectron. 2007, 23, 479-484.

(25) Leon, L. R.; Walker, L. D.; DuBose, D. A.; Stephenson, L. A. Am. J. Physiol. Regul. Integr. Comp. Physiol. 2004, 286, R967-974. 
nitrocellulose (collodion) using a protocol previously described by Dittmar and co-workers ${ }^{26}$ for making $\mathrm{O}_{2}$ microsensors. Collodion is a highly hydrophobic cellulose-based membrane. Small charged molecules (ions) and gases $\left(\mathrm{O}_{2}\right)$ can permeate the membrane which acts as a barrier for bigger organic molecules such as proteins, reducing a possible poisoning of the WE surface. ${ }^{26}$ The oxygen microsensor characteristics were evaluated up to 1 week in vitro, showing good accuracy and precision. Cyclic voltammetry, performed at $\mathrm{pH}$ 7.4, showed sensor response to $\mathrm{O}_{2}$ similar to that obtained by other research groups on glassy carbon electrodes ${ }^{24,27}$ suggestive of a two-step $\mathrm{O}_{2}$ reduction. ${ }^{28}$ The in vivo drop in sensitivity $(\sim-18 \%$ after 7 days of implantation in the striatum) was higher than the in vitro decrease measured at the same time $(\sim-11 \%$, data not shown), confirming a mild fouling process of the sensor surface despite the collodion coating. As detailed in the Experimental Section and Results sections, quiescent calibrations, performed using low and high $\mathrm{O}_{2}$ concentrations at different times, were used to estimate oxygen concentration in vivo. Further studies are necessary for evaluating the long-term response of sensors to oxygen in vitro and in vivo and the sensor aging process.

Striatal Oxygen Changes after Physiological Stimulations and Pharmacological Treatments. Several authors ${ }^{1,9,29-31}$ reported that basal oxygen concentration, recorded in the extracellular space of the striatum, is relatively low $(\sim 50 \mu \mathrm{M})$; these observations are in agreement with the findings of the present study. Striatal oxygen dynamics, following physiological stimulations, resulted in a rise in the local $\mathrm{O}_{2}$ signal. This result seems to be in opposition with the fact that during neural activation we would expect an increase of oxygen consumption and a consequential decrease in its extracellular concentration. However, $\mathrm{O}_{2}$ tissue concentration is regulated by the balance between blood supply and local utilization. ${ }^{1,9}$ In agreement with previous reports, ${ }^{1,9}$ during neural activation the increase in $\mathrm{rCBF}$ is greater than local utilization. These findings indicate that, under physiological stimulations, local $\mathrm{O}_{2}$ changes can be used as an index of $\mathrm{rCBF}$ but only when the oxygen supply significantly exceeds its utilization. ${ }^{1,9}$ Direct-administration of $\mathrm{O}_{2}$ (or $\mathrm{N}_{2}$ ) to a freely moving rat produced mild hyperoxia (or hypoxia) and

(26) Dittmar, A.; Mangin, S.; Ruban, C.; Newman, W. H.; Bowman, H. F.; Dupuis, V.; Delhomme, G.; Shram, N. F.; Cespuglio, R.; Jaffrezic-Renault, N.; Roussel, P.; Barbier, D.; Martelet, C. Sens. Actuators, B: Chem. 1997, 44, 316-320.

(27) Cui, H. F.; Ye, J. S.; Zhang, W. D.; Wang, J.; Sheu, F. S. J. Electroanal. Chem. 2005, 577, 295-302.

(28) Postlethwaite, T. A.; Hutchison, J. E.; Murray, R. Anal. Chem. 1996, 68, 2951-2958.

(29) Lowry, J. P.; Fillenz, M. Bioelectrochemistry 2001, 54, 39-47.

(30) Lowry, J. P.; Fillenz, M. J. Physiol. 1997, 498, 497-501.

(31) Dixon, B. M.; Lowry, J. P.; O’Neill, R. D. J. Neurosci. Methods 2002, 119, 135-142. resulted in an immediate and significant increase (or decrease) of the oxygen signal until the pure gas was substituted with air. This evidence indicates both the fast response time of $\mathrm{O}_{2}$ microsensors and the immediate transport of inhaled gases to the brain and confirmed previous studies on "wired" awake rats. ${ }^{9}$

Systemic administration of acetazolamide induced a sustained increase of striatal oxygen, confirming previous results obtained using carbon paste $\mathrm{O}_{2}$ sensors in freely moving rats. ${ }^{9,31}$ Acetazolamide (Diamox) is a carbonic anhydrase inhibitor that prevents the conversion of $\mathrm{CO}_{2}$ and $\mathrm{H}_{2} \mathrm{O}$ in $\mathrm{H}_{2} \mathrm{CO}_{3}$ and $\mathrm{H}^{+}$. In addition, acetazolamide forces the kidneys to eliminate $\mathrm{H}_{2} \mathrm{CO}_{3}$ with the concomitant acidification of the blood. The accumulation of $\mathrm{CO}_{2}$ in the organism induces hyperventilation and an increase in brain oxygen concentration; for this reason acetazolamide is the most used drug for altitude sickness prevention and treatment. $^{23}$

\section{CONCLUSIONS}

In this study we present a novel biotelemetric device for the real-time detection of brain oxygen in freely moving rats. The transmitter and the receiver units can be used for accurate transduction of the cathodic currents generated on the surface of $\mathrm{O}_{2}$ microsensors. This implantable device consists of two parts that, when assembled, polarize the sensor and send oxygenreduction data to a receiving unit connected to a PC. The systems electronics were tested under different experimental conditions exhibiting low power consumption, high stability, and good linear response. The in vivo results confirmed previously published observations on striatal oxygen dynamics. This apparatus, based on simple and inexpensive components, could be used as a rapid and reliable model for studying the effects of different drugs on brain oxygen dynamics.

\section{ACKNOWLEDGMENT}

The authors acknowledge the Italian distributors of National Corporations for free samples of integrated circuits. The research was supported by the Ministero dell'Istruzione, dell'Università $\mathrm{e}$ della Ricerca (PRIN 2007 fund), University of Sassari (ex 60\% fund), and Fondazione Banco di Sardegna.

\section{SUPPORTING INFORMATION AVAILABLE}

Additional information as noted in text. This material is available free of charge via the Internet at http://pubs.acs.org.

Received for review November 11, 2008. Accepted January 10, 2009.

AC802390F 